\title{
Cordyceps sinensis promotes immune regulation and enhances bacteriostatic activity of PA-824 via IL-10 in Mycobacterium tuberculosis disease
}

\author{
D.G. Li and Z.X. Ren \\ Department of Respiratory Medicine, East Medical District of Linyi People’s Hospital, Linyi, Shandong, China
}

\begin{abstract}
PA-824 is a novel bicyclic nitroimidazole anti-tuberculosis (TB) drug. Cordyceps sinensis (Berk.) Sacc. (CS) was proven to be a good immunomodulatory compound. This research aimed to investigate the effect of CS on PA-824 in Mycobacterium tuberculosis (M.tb) infected mice (female CBA/J mice, 6 to 8 weeks of age and $20 \pm 2 \mathrm{~g}$ of weight). Mice were randomly assigned to 4 groups: PA-824, CS, PA- $824+\mathrm{CS}$, and control. To verify the effect of PA-824 and CS on M.tb, after drug administration, mice lungs were harvested and bacterial colony formations were measured. Cells were isolated from infected lungs and spleens to analyze the percentage of $\mathrm{CD}^{+}{ }^{+} \mathrm{T}$ cells (CD11a positive). Lung cells were cultured to detect the secretion of interferon- $\gamma\left(\right.$ IFN- $\gamma$ ) and interleukin-10 (IL-10) by ELISA. IFN- $\gamma$ and IL-10 double-positive CD4 ${ }^{+}$cells in peripheral blood were measured by flow cytometry. The expression levels of IL-2 and IL-10 in mice lungs were analyzed by real-time PCR and western blot. Results showed that PA-824 combined with CS led to the lowest lung colony-forming units (CFU) counts among treated groups. Furthermore, this beneficial outcome might be associated with the decreased CD11a on CD4 ${ }^{+}$cells in mice lungs and spleens. Moreover, the suppressed secretion of IFN- $\gamma$ and IL-10, and IL-10 expressions, as well as the decreased IFN- $\gamma$ and IL-10 double-positive CD4 ${ }^{+}$cells in blood, could also be associated with the positive effect. However, no significant effect on IL-2 production was found. The combination of PA-824 and CS had more effective bacteriostatic and immunomodulatory effects on M.tb infected mice than PA-824 alone. In conclusion, CS has the potential to be an effective adjuvant in TB treatment.
\end{abstract}

Key words: Mycobacterium tuberculosis; Cordyceps sinensis (Berk.) Sacc.; PA-824; IFN- $\gamma$; IL-10

\section{Introduction}

Tuberculosis (TB) is still a major global health problem even with the slightly decreasing incidence in recent years (1). Anti-TB therapy relies on combined effect of bactericidal and anti-inflammatory drugs that can effectively reduce drug-resistance. The crucial point of TB treatment regimen is security and practicability. Ideally, a novel drug should be able to interact with other drugs freely, and without competing with or causing resistance of current drugs, especially multidrug-resistance. The nitroimidazooxazine PA-824 represents a new class of anti-tubercular drugs (2). PA-824 is one of the novel bicyclic nitroimidazole drugs for TB treatment that has already been in phase II clinical trials, and the other one is OPC-67683 (3). PA-824 has potent activity against Mycobacterium tuberculosis (M.tb) in vitro, and does not demonstrate cross-resistance to a variety of commonly used anti-TB drugs $(4,5)$. Although antibacterial activity of PA-824 to M.tb and multidrug resistance were evaluated, the exact mechanism is not well known $(6,7)$.
Cordyceps sinensis (Berk.) Sacc. (CS) is a Chinese herbal. As an insect parasitizing fungus, it belongs to the ascomycete family, and is found at high altitudes in the Qinghai-Tibetan plateau. CS has a long reputation for being one of the most expensive raw materials used in Oriental Medicine (8). CS has a number of far reaching medicinal effects that have been proven by modern technical methods. For example, some water extracts of CS might be beneficial in the prevention of tumor metastasis (9). CS has already been used in respiratory ailment treatments, such as cough and phlegm, shortness of breath, bronchial discomfort, chronic obstructive pulmonary disease, and asthma $(10,11)$. It also has been demonstrated that CS inhibits inflammatory reaction and prevented ischemic injury of many organs (12). However, the understanding of CS efficacy remains incomplete, as modern science attempts to investigate its effects in traditional medicine. 
This study aimed to verify the antibacterial and immune regulation activities of CS on PA-824 application in M.tb infected mice.

\section{Material and Methods}

\section{Preparation of PA-824 solution and CS extraction}

The pure powder of PA-824 was provided by the Global Alliance for TB Drug Development through Research Triangle International (RTI Park, USA). For administration in mice, PA-824 was suspended in a cyclodextrin micelle formulation (CM-2) containing 10\% hydroxypropyl- $\beta$ cyclodextrin (Sigma, USA) and 10\% lecithin (ICN Pharmaceuticals Inc., USA) as previously described (13), and the suspensions were stored at $4^{\circ} \mathrm{C}$. Aliquots were diluted in distilled water to the desired concentrations for dosing suspensions, and samples were shaken to ensure uniform dosing for oral administration.

CS produced in Qinghai, China, was purchased from the local wholesale distributor (Qinghai Cordyceps sinensis Technology Development, China). To obtain the extract of CS, $50 \mathrm{~g}$ of CS was dissolved in $100 \mathrm{~mL}$ distilled water. The CS solution was heated at $90^{\circ} \mathrm{C}$ for $2 \mathrm{~h}$ and concentrated by rotary evaporator (Eyela, Japan). Microfiltration was performed to remove bacteria and samples were lyophilized for $24 \mathrm{~h}$. The CS extractions, weighting $13.6 \mathrm{~g}$ $(27.2 \%)$ were diluted by adding distilled water to the concentrations that needed for esophageal gavage (14).

\section{Mice}

All in vivo experiments were performed in pathogenfree female CBA/J mice (National Cancer Institute, USA), 6 to 8 weeks of age and $20 \pm 2 \mathrm{~g}$ of weight. The mice were maintained under level 3 biohazard conditions, provided with sterile chow and water ad libitum, and housed in constant temperature and humidity with 12-h light-dark cycling. The pathogen-free nature of the mouse was demonstrated by testing sentinel animals. All experimental protocols were approved by local Animal Care and Use Committee.

\section{Bacterial infections}

M.tb strain Erdman (TMCC 107) was grown from low-passage seed lots in Proskauer-Beck liquid media (Seebio Biotech, China) containing $0.02 \%$ Tween 80 (Sigma) to mid-log phase, then frozen at $-70^{\circ} \mathrm{C}$ until use. The $\mathrm{CAB} / \mathrm{J}$ mice were infected with M.tb via the aerosol route by using the Inhalation Exposure System (Glas-Col, Inc., USA), with $5 \mathrm{~mL}$ of distilled water containing a suspension of bacteria that delivered about 100 bacteria/lung as previously described (15).

\section{PA-824 and CS intervention}

Infected mice were randomly divided into four groups: control (no treatment), PA-824 (10 mg/kg), CS (200 mg/kg) and PA-824 + CS (combination of $10 \mathrm{mg} / \mathrm{kg}$ PA-824 and
$200 \mathrm{mg} / \mathrm{kg} \mathrm{CS}$ ). Treatment with PA-824 and/or CS started at the 20th day after infection, and was administered by esophageal gavage once daily (7 days/week for 8 weeks). Five additional mice were sacrificed before treatment to determine the bacterial load in the lungs. Quantitative cultures were performed by plating serial dilutions of individual partial organ homogenates onto nutrient Middlebrook 7H11 agar (Sigma-Aldrich, USA) with selective antibiotics as previously described $(16,17)$, and bacterial colony formations were counted at the end of treatment. Data of lung bacterial colony-forming units (CFU) are reported as the $\log _{10}$ value of the mean number of bacteria recovered from four individual mice.

\section{Cells isolation from infected lung and spleen}

Mice were euthanized by $\mathrm{CO}_{2}$ asphyxiation and the pulmonary cavities were opened. The lungs were then cleared of blood by pulmonary artery perfusion with $10 \mathrm{~mL}$ of saline containing $50 \mathrm{U} / \mathrm{mL}$ of heparin (Sigma). Then the lungs were harvested and placed in cold DMEM (Gibco, USA). After the connective tissue and trachea were removed, the lungs were disrupted by using sterile razor blades, and incubated for $30 \mathrm{~min}$ at $37^{\circ} \mathrm{C}$ in DMEM medium. Single cell suspensions were obtained from the lung tissue by using collagenase/DNase as previously described (18). Spleens were also harvested from mice and the cells dispersed via a nylon screen. Red blood cells were lysed using ammonium-chloride-potassium (ACK) lysis buffer (Sigma) and spleen cells were re-suspended in DMEM plus supplements (Gibco).

\section{Flow cytometry}

Isolated cells for flow cytometry tests were obtained from lung or spleen and incubated with specific RPMI (Irvine Scientific, USA) supplemented with $0.1 \%$ sodium azide (Sigma-Aldrich) as previously described (18). Specific antibodies were purchased from BD Biosciences (PharMingen, USA): fluorescein isothiocyanate (FITC) labeled anti-CD11a (clone 2D7), and peridinin chlorophyll-protein labeled antiCD4 (clone RM4-5). Appropriate isotype control antibodies (Ag, $25 \mu \mathrm{g} / \mathrm{mL}$ ) were included in each analysis. Cells were analyzed using a FACS Calibur (BD Biosciences, USA) and data were analyzed using Cell Quest software (Becton Dickinson, USA).

\section{Lung cells culture}

Lung cells were suspended at $5 \times 10^{6}$ cells $/ \mathrm{mL}$ in DMEM plus supplements (Gibco) and cultured with ovalbumin (OVA, $10 \mu \mathrm{g} / \mathrm{mL}$, Sigma-Aldrich) or culture filtrate proteins from M.tb culture $(10 \mu \mathrm{g} / \mathrm{mL})$ for 5 days at $37^{\circ} \mathrm{C}$ with $5 \% \mathrm{CO}_{2}$.

\section{Cytokine ELISA analysis}

Supernatants of lung cell culture were harvested and the presence of interferon- $\gamma($ IFN- $\gamma)$ and IL-10 were measured by ELISA. The primary antibodies IFN- $\gamma$ (clone 
R4-6A2) and IL-10 (clone JES5.2A5) from BD PharMingen were used. The samples were dispensed in duplicate into the wells and standard curve was prepared using IFN- $\gamma$ or IL-10 for each individual plate. Cytokine production was detected by the addition of a secondary biotinylated antibodies (IFN- $\gamma$, clone XMG1.2; IL-10, clone SXC-1; BD PharMingen) and followed by avidin-peroxidase and $3,3^{\prime}, 5,5^{\prime}$-tetramethylbenzidine (TMB) substrate system (Sigma).

\section{IFN- $\gamma$ and IL-10 double-positive $\mathrm{T}$ cell detection}

For cellular characterization of $\mathrm{T}$ cells in mice after bacterial infection and drug administration, the following murine anti-human monoclonal antibodies of IFN- $\gamma$ and IL-10 (Becton Dickinson, Belgium) were used to direct immunofluorescence staining. In briefly, peripheral blood mononuclear cells from heparinized blood were obtained on a density gradient by Lymphoprep (Nicomed Pharma AS, Norway) as previously described (19). Negative controls included un-stimulated cells. The cells were suspended in RPMI 1640 and incubated for $16 \mathrm{~h}$ at $37^{\circ} \mathrm{C}$. Then, cells were stained for membrane marker CD4 ${ }^{+}$ T cells for $30 \mathrm{~min}$ at $4^{\circ} \mathrm{C}$, followed by fixation for $10 \mathrm{~min}$ at room temperature using lyse/fix solution (Becton Dickinson). Next, permeabilization was performed using Perm 2 solution (Becton Dickinson) for $10 \mathrm{~min}$ at room temperature. After staining with anti-IFN- $\gamma$ and anti-IL-10 antibodies for $1 \mathrm{~h}$ at $4^{\circ} \mathrm{C}$, flow cytometric analysis was performed (20).

\section{Real-time PCR}

Right medial lung lobes were homogenized in $1 \mathrm{~mL}$ of Ultraspec (Biotecx Laboratories, USA) and frozen rapidly at $-80^{\circ} \mathrm{C}$. Total cellular RNA was extracted from the homogenate and reverse transcribed by using the Omniscript RT kit (Qiagen, Germany) following the manufacturer's instructions. Real-time PCR was performed using an iQ5 real-time PCR detection system (Bio-Rad, USA) using Taq-Man gene expression assays for Interleukin-2 (IL-2) and IL-10. The $2^{-\Delta \Delta \mathrm{Ct}}$ method was used for relative quantification of mRNA expression and GAPDH was used as internal control (21).

\section{Western blot}

The total proteins of right medial lung lobes were extracted according to the manufacturer's protocol and the samples were detected using Pierce ${ }^{\mathrm{TM}}$ BCA Protein Assay Kit (Thermo Fisher Scientific, USA). Equal amounts of proteins $(100 \mu \mathrm{g})$ were separated by sulfate-polyacrylamide gel electrophoresis and transferred onto nitrocellulose membranes. Western blotting was performed by standard techniques as described previously (22). The primary antibodies (1:1000) against IL-2 (D7A5), IL-10 (D13A11) and GAPDH (14C10) (Cell Signaling Technology, USA) were used followed with second antibody HRP goat anti-rabbit (1:1000, Cell Signaling Technology). All results are reported as changes of fluorescent band intensity of target antibody to GAPDH, which was used as an internal control. All sample bands intensity quantification was performed by using ImageJ software (National Institutes of Health, USA).

\section{Statistical analyses}

Statistical analyses were performed by using Graphpad Prism 5 (Graphpad Software, USA). Results are reported as means $\pm S D$. Student's $t$-test was used for pairwise comparisons, a one-way analysis of variance (ANOVA) was used for multi-group comparisons. A $P$ value of $<0.05$ was considered to be statistically significant.

\section{Results}

\section{CFU was decreased in mouse lungs after} administration of PA-824 and/or CS

As shown in Figure 1, after infection, lung bacterial CFU began to rise. Three weeks later, after PA-824 and/or CS treatment, the CFU counts were different among the 4 groups. After 8 weeks, lung CFU counts in mice lungs treated with PA-824 alone, CS alone and PA-824+CS were significantly decreased compared to the control group ( $\mathrm{P}<0.05$ or $\mathrm{P}<0.01$ ). More important, the $\mathrm{PA}-824+$ CS group showed the lowest CFU counts, which could be indicative of an enhanced effect of CS on bactericidal activity of PA-824.

\section{Expressions of CD11a on CD4 + cells in lung and spleen were suppressed following PA-824 and/or CS treatment}

To identify the mechanism by which treated mice could reduce the bacterial load in the lungs, we analyzed the

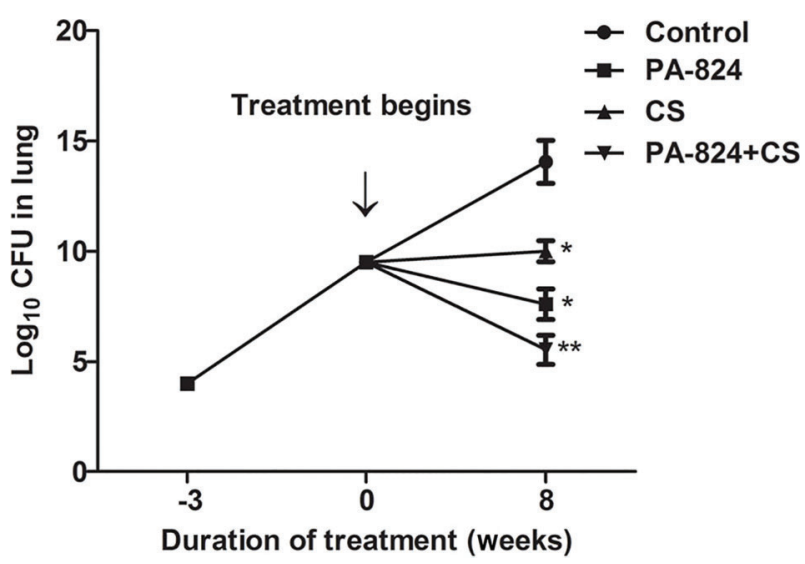

Figure 1. Quantitative analysis of colony-forming units (CFU) in mice lungs. Mice were infected with Mycobacterium tuberculosis Erdman strain for 3 weeks followed by 8 weeks of administration of PA-824, CS, or the combination of both. The bacterial CFU were decreased compared to the control without drug treatment. Data are reported as means \pm SD. CS: Cordyceps sinensis (Berk.) Sacc. ${ }^{*} \mathrm{P}<0.05,{ }^{\star \star} \mathrm{P}<0.01$, compared to control (ANOVA). 

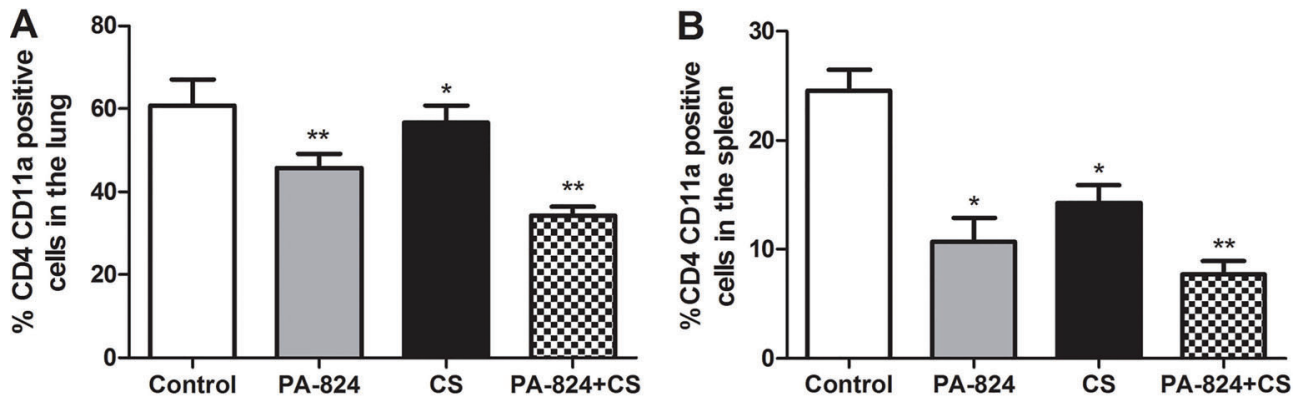

Figure 2. Expression of $\mathrm{CD} 11 \mathrm{a}$ on $\mathrm{CD} 4^{+}$T cells isolated from the lung and spleen after treatment with PA-824, CS or the combination of both. Lung cells $(A)$ and spleen cells $(B)$ were isolated from Mycobacterium tuberculosis-infected mice throughout the course of the treatment and labeled with fluorescent antibodies specific for CD4 and CD11a. Data are reported as means \pm SD percentage of CD4 positive cells that expressed a high level of CD11a on their surface. CS: Cordyceps sinensis (Berk.) Sacc. ${ }^{*} P<0.05$, ${ }^{* *} P<0.01$, compared to control (ANOVA).
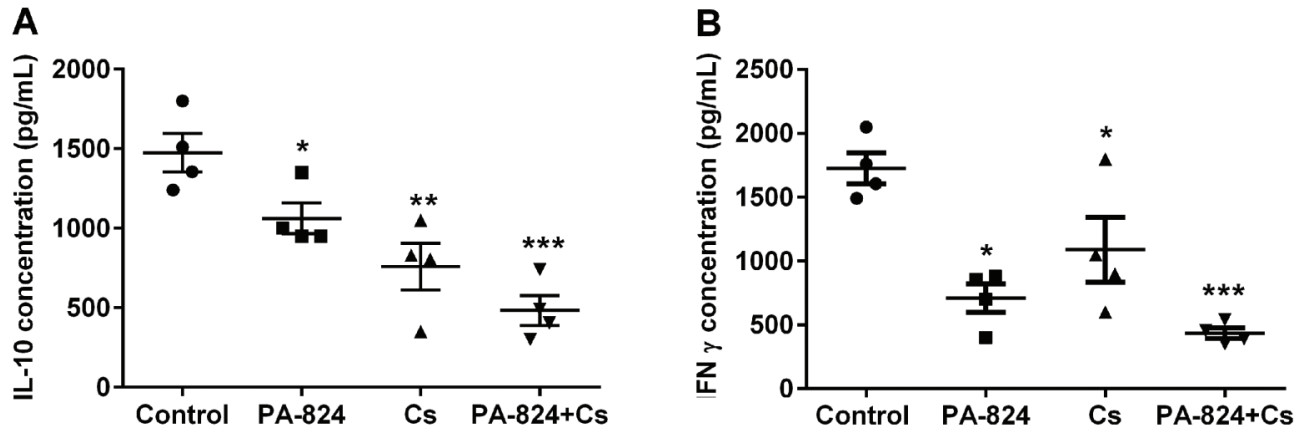

Figure 3. IL-10 and IFN- $\gamma$ secretions in the infected mice lungs after administration of PA-824, CS or the combination of both. Lung cells from individual mice were cultured and IL-10 $(A)$ and IFN- $\gamma(B)$ secretions in the cell culture supernatants were measured by ELISA. Data are reported as means \pm SD. CS: Cordyceps sinensis (Berk.) Sacc.; IFN- $\gamma$ : interferon- $\gamma$; IL-10: interleukin-10. ${ }^{*} \mathrm{P}<0.05$, ${ }^{* *} \mathrm{P}<0.01$; ${ }^{* * *} \mathrm{P}<0.001$, compared to control (ANOVA).

level of T lymphocyte subset CD4 that entered the lung and spleen after 8 weeks of treatment. Cell adhesion molecules have been shown to be involved in cell recognition, signaling and autoimmune diseases. In this study, $\mathrm{CD}^{+}{ }^{+}$T lymphocytes in lung were analyzed by measuring cell adhesion molecule CD11a expression. The group treated with PA-824 alone showed decreased CD11a expressions on $\mathrm{CD}^{+}{ }^{+}$cells in lung compared with the control group. Meanwhile, in the PA-824+CS group, the CD11a expressions on $\mathrm{CD}^{+}{ }^{+}$cells in lung were lower compared with the other groups $(P<0.01$ or $P<0.05$, Figure 2A). Analysis of the expressions of CD11a on $\mathrm{CD}^{+}$cells in the spleen of treated mice showed the similar result $(P<0.05$ or $P<0.01$, Figure $2 B)$. These results suggested that $\mathrm{PA}-824$ treatment decreased CD11a expressions on CD4 ${ }^{+}$T cells in lung and spleen and CS enhanced the efficacy of PA-824.

\section{IL-10 and IFN- $\gamma$ productions were altered by PA-824 and CS combined effect}

To evaluate the specific responses of lymphocytes in the lungs of mice following M.tb infection and after drug treatments, IFN- $\gamma$ and IL-10 productions in cultured lung cells were determined by ELISA. The results showed that IFN- $\gamma$ and IL-10 were significantly lower in both PA-824and CS-treated groups compared with the untreated control group $(\mathrm{P}<0.05$ or $\mathrm{P}<0.01)$, while in the $\mathrm{PA}-824+$ CS group, the content of IFN- $\gamma$ and IL-10 was reduced even more significantly $(P<0.001)$ (Figure $3 A$ and $B)$. Similar results were found in cellular immunologic response detection as shown in Figure 4 . The percentage of CD4 ${ }^{+}$ $\mathrm{T}$ cells (IFN- $\gamma$ and IL-10 double positive) in blood was decreased after PA-824 or CS administration compared with the untreated control group $(P<0.05$, or $P<0.01)$. Moreover, in the PA-824 + CS group, the number of IFN- $\gamma$ and IL-10 double positive-CD4 ${ }^{+}$cells was the lowest of the 4 groups. These results suggested that CS could enhance the anti-inflammation effect of PA-824 in vitro and in vivo.

\section{Decreased IL-2 and IL-10 expressions in infected mice lungs after treatment with PA-824 and CS}

To quantify cytokine production in the lung cells after treatment, cytokine expression levels in lung homogenates 


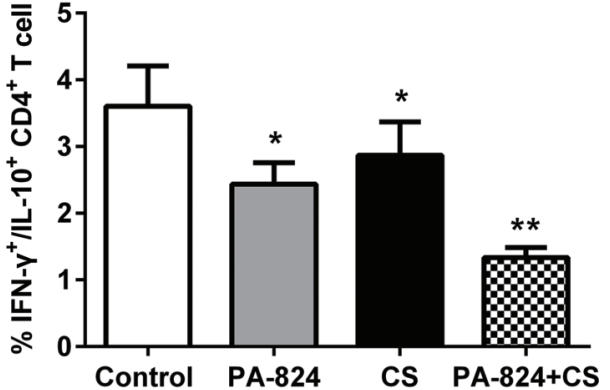

Figure 4. Relative IFN- $\gamma$ and IL-10 double-positive $\mathrm{CD}^{+}$cells in peripheral blood of infected mice after administration of PA-824, $\mathrm{CS}$ or the combination of both, measured by flow cytometry. CS: Cordyceps sinensis (Berk.) Sacc.; IFN- $\gamma$ : interferon- $\gamma$; IL-10: interleukin-10. ${ }^{*} \mathrm{P}<0.05,{ }^{* *} \mathrm{P}<0.01$, compared to control (ANOVA).

were measured. RT-PCR results are shown in Figure $5 \mathrm{~A}$; mRNA expression levels of IL-10 in CS and PA-824+ CS groups were significantly decreased compared with control $(P<0.01)$. The level was lower in the PA-824+ CS group. However, no significant impact on IL-2 mRNA expression was found in the present experiment. Figure $5 \mathrm{~B}$ shows the results of protein immunoblot and quantification for IL-2 and IL-10 by western blot assay. Consistent with the result of RT-PCR, PA-824 and CS reduced the IL-10 protein expression level $(P<0.05$ or $P<0.001$ ), while no significant effects were found on IL-2. Even more important, protein expression level of IL-10 was the lowest in the PA-824 + CS group, suggesting that CS might enhance the efficacy of PA-824 via inhibition of IL-10 expression.

\section{Discussion}

Almost all anti-TB drugs used in regular clinics were developed more than 50 years ago. There is limited research assessing the potential of traditional Chinese medicine as TB drug adjuvants in murine models, which might provide the theoretical basis for their use in clinical treatment (23). Meanwhile, the wide usage of antibiotics has led to the widespread emergence of resistant bacteria, which is also one of the very important reasons for M.tb multiple drug resistance (24). The treatment of drugresistant TB by second-line drugs is an important component of TB control, as well as an integral part of the World Health Organization Stop TB Strategy (25). In order to effectively prevent and treat TB, anti-TB drugs with new structures or mechanisms are urgently needed. In this study, our results suggested that the antibacterial effect of PA-82 was enhanced by $\mathrm{CS}$ in M.tb infected murine model; we also present the possible mechanism.

PA-824 has a unique mechanism of action and has no cross-resistance to other existing TB drugs (4). In murine model, PA-824 was proved to have bactericidal activity during the initial and continuation phases of TB treatment (26).
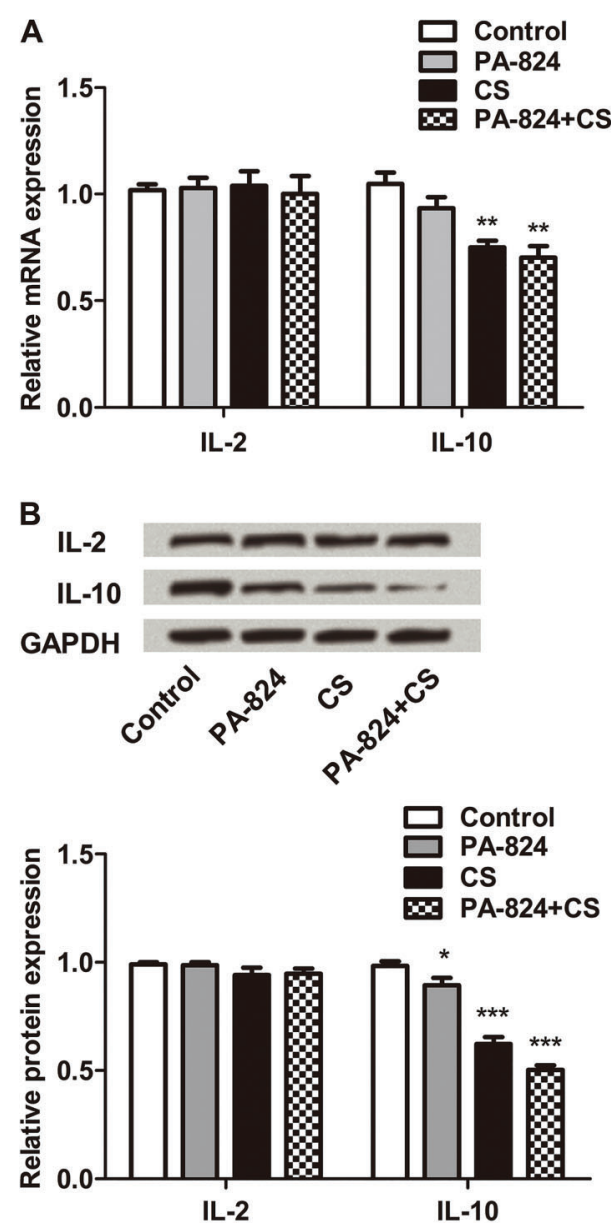

Figure 5. IL-2 and IL-10 expression in the lung during infection after administration of PA-824, CS or the combination of both. The mice lungs after treatment were stripped out and prepared for analysis. $A$, mRNA expression level of IL-2 and IL-10 in the mice lung by real-time PCR. $B$, Protein immunoblots and quantification of IL-2 and IL-10 in M.tb infected mice lungs after treatment. GAPDH acted as an internal control. CS: Cordyceps sinensis (Berk.) Sacc.; M.tb: Mycobacterium tuberculosis; IL-2: interleukin-2; IL-10: interleukin-10. ${ }^{*} \mathrm{P}<0.05$, ${ }^{\star *} \mathrm{P}<0.01$, ${ }^{* \star} \mathrm{P}<0.001$, compared to control (ANOVA).

PA-824 also showed activity against latent or persistent M.tb isolates in vivo (27). In the present study, our results suggested that the addition of CS to PA-824 caused a more effective reduction of $M$.tb colony formation in lungs than PA-824 alone. We also found that CD11a expression on $\mathrm{CD}^{+}{ }^{+}$cells was decreased after treatment with PA-824 and/or CS. CD11a, a cell adhesion molecule involved in cellular adhesion and costimulatory signaling, and that combines with CD18 to form the integrin lymphocyte function-associated antigen-1 (LFA-1) was expressed on all leukocytes. LFA-1 plays a central role in leukocyte intercellular adhesion, trafficking and activation through interactions with its ligands ICAMs 1-3 (intercellular adhesion 
molecules 1-3), and also functions in lymphocyte costimulatory signaling and thus it emerged as an attractive therapeutic target for treatment of multiple diseases (28). The decreased CD11a suggested that the inhibition effect of PA-824 + CS enhanced the influence of PA-824 on TB infected mice lymphocyte.

CS has a variety of pharmacological effects, such as anti-inflammatory action, anti-apoptotic effect, stimulation of natural killer cells, and antitumor activity (12,29-31). CS anti-TB capsule combined with chemotherapy promoted a focused absorption, increased the sputum conversion rate, improved symptoms and enhanced the immunity of TB patients, suggesting better therapeutic effect compared with modern clinical drugs (32). IFN- $\gamma$ is a cytokine with strong resistance to pathogenic microorganisms. IFN- $\gamma$ is secreted by innate immune cells such as dendritic cells, antigen-presenting cells, and adaptive immune cells such as CD4 ${ }^{+} \mathrm{T}_{\text {cell }}$ and CD8 ${ }^{+}$T cells. IL-10 is a multifunctional negative regulatory cytokine. Our results suggested that contents of IFN- $\gamma$ and IL-10 in the supernatant of lung cell culture were decreased after drugs treatments. CS administration showed a more significant reduction of IFN- $\gamma$ and IL-10 contents. It indicated that CS enhanced the action of PA-824 in murine lung cellular immune response.

As previously reported, IFN- $\gamma^{+}$and $\mathrm{IL}-10^{+}$doublepositive cells regulate immune responses to certain infections. For example, patients with either acute pulmonary tuberculosis, Borrelia burgdorferi or Leishmania visceralis infection expressed pathogen-specific IL- $10^{+}$and IFN- $\gamma^{+}$ double-positive IFN- $\gamma$-secreting T helper 1 (Th1) cells in the blood and lung (33). In this study, our results suggested that IL-10 ${ }^{+}$and IFN- $\gamma^{+}$double-positive $\mathrm{CD} 4{ }^{+}$ $T$ cells were decreased after PA-824 administration, and CS further enhanced PA-824 effect, suggesting that CS enhanced the regulation effect of PA-824 on cell-mediated immune response in TB injected mice.

\section{References}

1. Behera D. Global Tuberculosis Control 2011, WHO Report 2011. Indian J Med Res 2012.

2. Kang YG, Park CY, Shin H, Singh R, Arora G, Yu CM, et al. Synthesis and anti-tubercular activity of 2-nitroimidazooxazines with modification at the C-7 position as PA-824 analogs. Bioorg Med Chem Lett 2015; 25: 3650-3653, doi: 10.1016/j.bmcl.2015.06.060.

3. Matsumoto $M$, Hashizume $H$, Tomishige $T$, Kawasaki $M$, Tsubouchi H, Sasaki H, et al. OPC-67683, a nitro-dihydroimidazooxazole derivative with promising action against tuberculosis in vitro and in mice. PLoS Med 2006; 3: 21312144, doi: 10.1371/journal.pmed.0030466.

4. Stover CK, Warrener $P$, Vandevanter DR, Sherman DR, Arain TM, Langhorne $\mathrm{MH}$, et al. A small-molecule nitroimidazopyran drug candidate for the treatment of tuberculosis. Nature 2000; 405: 962-966, doi: 10.1038/35016103.

5. Manjunatha U, Boshoff HI, Barry CE. The mechanism of action of PA-824: Novel insights from transcriptional profilinf.
The results showed that the expression of IL-10 in mice lung was significantly decreased, while there was no significant impact on IL-2. IL-10 is a potent immunomodulatory cytokine that directly or indirectly affects multiple cells in vitro (34). IL-10 is produced by a range of CD4 ${ }^{+}$ T cell subsets, as well as by macrophages, dendritic cells, eosinophils B cells and mast cells; the major source of IL-10 is $\mathrm{CD}^{+}$Treg cells (33). IL-10 has broad antiinflammatory properties, one of which is to counteract the function of Th1 lymphocytes. It has the dominant function to deactivate macrophages, resulting in diminished Th1 cytokine production, which might have far-reaching consequences on both innate and acquired immunity in vivo (21). In this regard, the immunosuppressive activity of IL-10 might contribute to mycobacterial disease (35). Research suggests that pathogens might cause high IL-10 expression to better sustain the infection process $(36,37)$. Meanwhile, it has been suggested that removal of IL-10 enhanced protective immunity (38). Consistent with these studies, our results showed that PA-824 and CS suppressed the expression level of IL-10 in M.tb infected mice, and more importantly, the combination of PA-824 and CS significantly deepened this inhibition. These results imply that the effect of PA-824 on cellular immunologic response that was enhanced by CS might be related with the suppressed expression of IL-10.

In this study, the main finding was the enhanced activity of PA-824 by CS. As a traditional Chinese herbal, CS proved to be effective in promoting the PA-824 efficacy in the treatment of M.tb disease. In the development of anti-TB drugs, a major priority should be the ability to shorten the duration of TB treatment. Our results might also provide new perspectives for the use of traditional Chinese medicines combined with modern clinical drugs during clinical therapy, which might shorten the duration of tuberculosis treatment.

Commun Integr Biol 2009; 2: 215-218, doi: 10.4161/cib.2. 3.7926 .

6. Manjunatha UH, Boshoff H, Dowd CS, Zhang L, Albert TJ, Norton JE, et al. Identification of a nitroimidazo-oxazinespecific protein involved in PA-824 resistance in Mycobacterium tuberculosis. Proc Natl Acad Sci USA 2006; 103: 431-436, doi: 10.1073/pnas.0508392103.

7. Choi KP, Kendrick N, Daniels L. Demonstration that fbiC Is Required by Mycobacterium bovis BCG for coenzyme F420 and FO biosynthesis. J Bacteriol 2002; 184: 2420-2428, doi: 10.1128/JB.184.9.2420-2428.2002.

8. Cleaver JHM. Medicinal Value of the caterpillar fungi species of the genus Cordyceps (Fr) Link (Ascomycetes). A Review. Med Mushrooms 2008; 10: 219-234, doi: 10.1615/IntJMed Mushr.v10.i3.30.

9. Nakamura K, Konoha K, Yamaguchi Y, Kagota S, Shinozuka $\mathrm{K}$, Kunitomo MCombined effects of Cordyceps sinensis and methotrexate on hematogenic lung metastasis in mice. 
Receptors Channels 2003; 9: 329-234, doi: 10.3109/7137 45176.

10. Wei MU, Song YL, Zhang S, Zhang L, Min FU, Shang HC. Cordyceps sinensis for chronic obstructive pulmonary diseases: a systematic review. Chinese $J$ Evidence-Based Med 2013; 13: 1373-1381.

11. Choeng Huaisen LZ, Kim Sangcan. Effects of Cordyceps sinensis water extract on the cytokine in ovalbumin-induced asthma mouse. Physiol Pathol 2006; 20.

12. Shahed AR, Kim SI, Shoskes DA. Down-regulation of apoptotic and inflammatory genes by Cordyceps sinensis extract in rat kidney following ischemia/reperfusion. Transplant Proc 2001; 33: 2986-2987.

13. Tyagi S, Nuermberger E, Yoshimatsu T, Williams K, Rosenthal I, Lounis N, et al. Bactericidal activity of the nitroimidazopyran PA-824 in a murine model of tuberculosis. Antimicrob Agents Chemother 2005; 49: 2289-2293, doi: 10.1128/AAC.49.6.2289-2293.2005.

14. Gu YY, Wang $H$, Wang $S$, Gao $H$, Qiu MC. Effects of Cordyceps sinensison the expressions of NF-kB and TGF- $\beta 1$ in myocardium of diabetic rats. Evid Based Complement Alternat Med 2015; 2015: 369631, doi: 10.1155/2015/369631.

15. Gonzalez-Juarrero M, Shim TS, Kipnis A, Junqueira-Kipnis AP, Orme IM. Dynamics of Macrophage cell populations during murine pulmonary tuberculosis. J Immunol 2003; 171: 3128-3135, doi: 10.4049/jimmunol.171.6.3128.

16. Ahmad Z, Nuermberger EL, Tasneen R, Pinn ML, Williams $\mathrm{KN}$, Peloquin CA, et al. Comparison of the 'Denver regimen' against acute tuberculosis in the mouse and guinea pig. J Antimicrob Chemother 2010; 65: 729-734, doi: 10.1093/ $\mathrm{jac} / \mathrm{dkq} 007$.

17. Nuermberger E, Rosenthal I, Tyagi S, Williams KN, Almeida $\mathrm{D}$, Peloquin CA, et al. Combination chemotherapy with the nitroimidazopyran PA-824 and first-line drugs in a murine model of tuberculosis. Antimicrob Agents Chemother 2006; 50: 2621-2625, doi: 10.1128/AAC.00451-06.

18. Vesosky B, Flaherty DK, Turner J. Th1 cytokines facilitate CD8-T-cell-mediated early resistance to infection with Mycobacterium tuberculosis in old mice. Infect Immun 2006; 74: 3314-3324, doi: 10.1128/IAI.01475-05.

19. Tucker V, Jenkins J, Gilmour J, Savoie H, Easterbrook $\mathrm{P}$, Gotch $\mathrm{F}$, et al. T-cell telomere length maintained in HIVinfected long-term survivors. HIV Med 2000; 1: 116-122, doi: 10.1046/j.1468-1293.2000.00010.x.

20. Cools N, Tendeloo VFIV, Smits ELJM, Lenjou M, Nijs G, Bockstaele DRV, et al. Immunosuppression induced by immature dendritic cells is mediated by TGF- $\beta / \mathrm{IL}-10$ doublepositive CD4 + regulatory T cells. J Cell Mol Med 2008; 12: 690-700, doi: 10.1111/j.1582-4934.2007.00084.x.

21. Gillian L. Beamer DKF, Barnabe D. Assogba et al. Interleukin-10 promotes Mycobacterium tuberculosis disease progression in CBA/J mice. $J$ Immunol 2008; 181: 55455550, doi: 10.4049/jimmunol.181.8.5545

22. Doiz O, Benito R, Sbihi Y, Osuna A, Clavel A, Gómez-Lus R. Western blot applied to the diagnosis and post-treatment monitoring. Diagn Microbiol Infect Dis 2001; 41: 139-142, doi: 10.1016/S0732-8893(01)00293-0.

23. Li Siyang JX, Li Zhuorong. The research progress of effective ingredients of traditional Chinese medicine against tuberculosis. Chinese J Antibiotics 2013; 38: 725-729.
24. Shin SS, Keshavjee S, Gelmanova IY, Atwood S, Franke MF, Mishustin SP, et al. Development of extensively drugresistant tuberculosis during multidrug-resistant tuberculosis treatment. Am J Respir Crit Care Med 2010; 182: 426432, doi: 10.1164/rccm.200911-17680C.

25. WHO. The stop TB strategy: building on and enhancing DOTS to meet the TB-related millenium development goals. Geneva: World Health Organization; 2006.

26. Ahmad Z, Peloquin CA, Singh RP, Derendorf H, Tyagi S, Ginsberg A, et al. PA-824 exhibits time-dependent activity in a murine model of tuberculosis. Antimicrob Agents Chemother 2011; 55: 239-245, doi: 10.1128/AAC.00849-10.

27. Lenaerts AJ, Gruppo V, Marietta KS, Johnson CM, Driscoll DK, Tompkins NM, et al. Preclinical testing of the nitroimidazopyran PA-824 for activity against Mycobacterium tuberculosis in a series of in vitro and in vivo models. Antimicrob Agents Chemother 2005; 49: 2294-2301, doi: 10.1128/AAC.49.6.2294-2301.2005.

28. Giblin PA, Lemieux RM. LFA-1 as a key regulator of immune function: approaches toward the development of LFA-1based therapeutics. Curr Pharm Des 2006; 12: 2771-2795, doi: $10.2174 / 138161206777947731$.

29. Zhao YL, Yang LM, Zhou Y, Sun XZ, Luo SM. Effects of Cordyceps sinensis Berk.Sacc on expression of TGF- $\beta$ _1 and VEGF in liver fiberosis. Progr Modern Biomed 2012.

30. Chen YC, Huang YL, Huang BM. Cordyceps sinensis mycelium activates PKA and PKC signal pathways to stimulate steroidogenesis in MA-10 mouse Leydig tumor cells. Int J Biochem Cell Biol 2005; 37: 214-223, doi: 10.1016/j.biocel.2004.05.019.

31. Jian YW, Qiao XZ, Leung PH. Inhibitory effects of ethyl acetate extract of Cordyceps sinensis mycelium on various cancer cells in culture and B16 melanoma in C57BL/6 mice. Phytomedicine 2007; 14: 43-49, doi: 10.1016/j.phymed.2005.11.005.

32. Wang Yuan DE, Jia Zhong. A retrospective analysis of cordyceps anti-tuberulosis capsule combined with chemotherapy for 614 cases of secondary tuberculosis. Tradit Chinese Med 2013; 54: 1304-1307.

33. Cope A, Le FG, Cardone J, Kemper C. The Th1 life cycle: molecular control of IFN- $\gamma$ to IL-10 switching. Trends Immunol 2011; 32: 278-786, doi: 10.1016/j.it.2011.03.010.

34. Moore KW, de Waal Malefyt R, Coffman RL, O'Garra A. Interleukin-10 and the interleukin-10 recptor. Annu Rev Immunol 2001; 19: 683-765, doi: 10.1146/annurev.immunol.19.1.683.

35. Rojas RE, Balaji KN, Subramanian A, Boom WH. Regulation of human CD4 $+\alpha \beta$ T-cell-receptor-positive $(\mathrm{TCR}+)$ and $\gamma \delta$ TCR + T-cell responses to Mycobacterium tuberculosis by interleukin-10 and transforming growth factor $\beta$. Infect Immun 1999; 67: 327-329.

36. Saraiva M, O'Garra A. The regulation of IL-10 production by immune cells. Nature Rev Immunol 2010; 10: 170, doi: 10.1038/nri2711.

37. Jankovic D, Kugler DG, Sher A. IL-10 production by CD4 + effector T cells: a mechanism for self-regulation. Mucosal Immunol 2010; 3: 239-246, doi: 10.1038/mi.2010.8.

38. Roach DR, Martin E, Bean AG, Rennick DM, Briscoe H, Britton WJ, et al. Endogenous inhibition of antimycobacterial immunity by IL-10 varies between mycobacterial species. Scand J Immunol 2001; 54: 163-170, doi: 10.1046/j.13653083.2001.00952.x. 